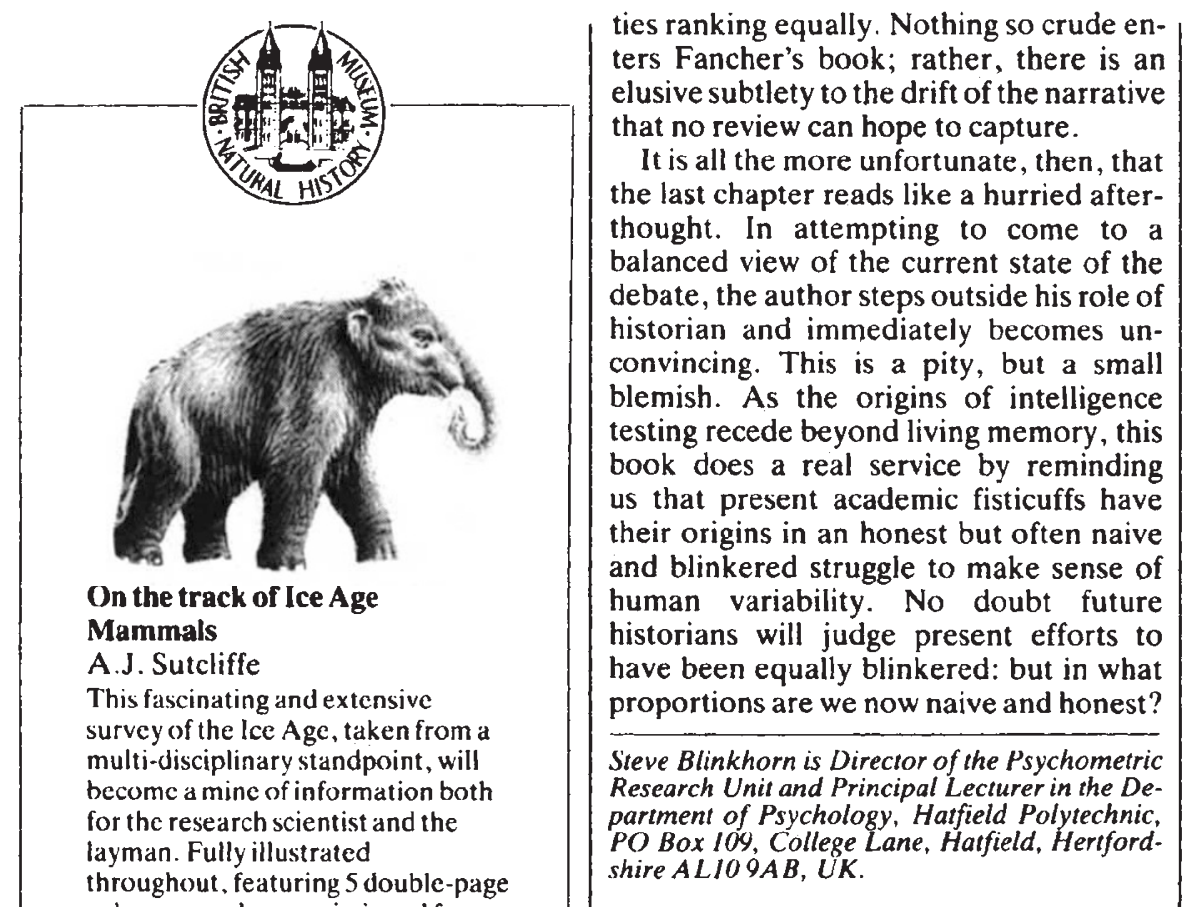

colour spreads commissioned from artist Peter Snowball.

$224 \mathrm{pp}, 150 \mathrm{~b} / \mathrm{w}$ illustrations +5

double pages colour.

() $5650(08692$. Hhk. $£ 12.95$

Crows of the World, 2nd ed.

Derek Goodwin

An up-dated edition of this standard reference work on the familiar yet diverse crow family. Includes 3 new colour plates commissioned from Robert Gillmor.

30)pp. approx. 6 colour plates. 1986 .

0.565 ()(1979 6. Hbk. approx. $£ 30 .(x)$

The Littoraria species of IndoPacific mangrove forests. D.G. Reid

A detailed study of 20 species of Litlorina scabra, many previously unrecognised, with particular attention to the reproductive system by which the species can be reliably distinguished. A key to shells is also provided.

$24(1) \mathrm{pp} .99$ illustrations, 1 colour plate.

$0565(0) 9788 . £ 35.00$

\section{A world list of mammalian} species, 2 nd ed.

\section{G.B. Corbet \& J.E. Hill}

New edition of this easy-to-use reference book designed primarily for the non-specialist. Incorporates many additions and revisions since the first edition of 1980.

240pp. approx. 1986

() $565($ () $) 9885 £ 25 .(0)$

Publications Salles. British Museum. (Natural Historyl. Crom wetl Roid. London SW7.5BD
The chapter on "The Ascendant Female Scientist" was, says the author. written against the strongly stated advice of all his female acquaintances, who were still smarting from a section entitled "Sex in the Laboratory" in his previous book. None of them, he says, would admit to the classification of "friend" after it was published.

Why, then he do it? The answer appears to be that Dr Sindermann is an oldfashioned scientific optimist who believes that all science is exciting and wonderful, and that anyone who succeeds in it is to be applauded and emulated. (In this he may have something in common with the august figure who once opined in print that it would be a pity for the world to blow itself up with nuclear weapons because that would halt the onward march of science.) Hardly anywhere in the book - whether discussing choice of research topic, career transitions or interactions with the outside world - does he discuss the problem of deciding whether a project is socially desirable. The word "ethics" does not appear in the index.

Dr Sindermann has little time for the also-rans, except as examples of where one can go wrong. He would certainly not agree with a friend of mine, who emerged limply from a two-hour session with a visiting celebrity to remark that the failures were much more interesting to talk to. He has harsh words to say about the Burnout, the Fade-out and the Guaranteed Loser. The latter category includes the Unwary Activist, who may (he says) damage his or her scientific credibility by espousing causes for social reform. The author classes such misguided people along with the Dilettante, the Hobbyist and the Chronic Underachiever.

Since most of us (by definition of that uncompromising word "excellence") are not going to reach Dr Sindermann's Valhalla of success, why should anyone read his book? The upwardly mobile graduate student with a taste for ruthless self-advancement will have his own ideas on how to make it. For those who have reached what the author calls the "midlife crisis" it is probably too late. The ageing scientist (to whom a chapter is devoted) is not going to believe a word of it.

Perhaps the most interesting thing about the book is what is missing from it. There is the same moral vacuum in the Royal Society's message to scientists, that they should learn how to manage the media in support of their chosen way of life. It is possible - just possible - that the current public mood of suspicion and alarm about the outcome of some scientific research is due not to inadequate public relations, but to a failure among scientists to think about the repercussions on ordinary people. Politicians have made the same mistake.

Michael Spencer is a voluntary exile from science based at 34 Bayham Road, Sevenoaks, Kent TN13 $3 X E$, UK. 